\title{
Korelasi Positif Perubahan Berat Badan Interdialisis dengan Perubahan Tekanan Darah Pasien Post Hemodialisa
}

\author{
Purnomo Widiyanto ${ }^{1}$, Hamam Hadi $^{2}$, Teguh Wibowo ${ }^{3}$ \\ 1, 2 Sekolah Tinggi IImu Kesehatan Alma Ata Yogyakarta \\ Jalan Ringroad Barat Daya No 1 Tamantirto, Kasihan, Bantul Yogyakarta \\ ${ }^{3}$ RSUD Saras Husada Purworejo
}

\begin{abstract}
Abstrak
Berat badan interdialysis digunakan sebagai dasar menentukan ultra filtrasi pada pasien hemodialisa. Ultra filtrasi yang berlebihan dapat mempengaruhi hemodinamik pasien. Menurut data Indonesian Renal Registry (IRR), pada tahun 2012 sebanyak 11\% pasien dengan hemodialisa mengalami hipotensi. Penelitian observasional analitik ini menggunakan design survey cohort bertujuan untuk menganalisis perubahan berat badan interdialisis dengan perubahan tekanan darah pasien post hemodialisis di RSUD Saras Husada Purworejo. Sebanyak 40 responden dalam penelitian terbagi menjadi dua kelompok dan ditentukan dengan tehnik purposive sampling sesuai dengan criteria inklusi dan ekslusi. Data survey kohort di analisis menggunakan Paired T-Test, Spearman Rank Test dan Chi Square dan didapatkan karakteristik subyek sebagai berikut; jenis kelamin $p=0,736$, umur $p=0,744$, riwayat $D M p=0,311$ dan riwayat $H T p=0,185$ artinya tidak terdapat hubungan yang signifikan dengan kenaikan $B B$ interdialisis $(p>0,05)$. Hubungan $B B$ interdialisis dengan perubahan $T D, R R=2,750 x^{2}=3,84$ dan $p=0,050(p=0,05)$ terdapat hubungan yang signifikan dengan arah+ positif. Simpulan penelitian ini adalah terdapat hubungan antara perubahan berat badan interdialisis dengan perubahan tekanan darah. Kelompok terpapar dengan kenaikan BB interdialisis $>8 \%$ terjadi hipotensi.
\end{abstract}

Keywords: BB interdialisis, Tekanan darah, Hemodialisis

\section{Positive Correlation of Changing Interdialysis Body Weight with the Changing of Post Dialysis Blood Pressure}

\begin{abstract}
Interdialysis body weight is used to determine ultra filtration speed on hemodialisa patients. The overload ultra filtration can influence patients hemodynamic. According to Renal Registry Indonesia, it was 11 percent in 2012 dialysis patients experienced hypotension. This observational analytic study used cohort survey aims to analyse changing of interdialysis body weight and of blood pressure among dialysis patients in RSUD Saras Husada Purworejo. In this research, 40 respondents divided into two groups by purposive sampling based on inclusion and exclusion criteria. Data was analysed using Paired T-Test, Spearman Rank Test and Chi Square and was obtained characteristics subject sexes $p=0.736, p=0.744$ age, history of diabetes $p=$ 0.311 and $p=0.185 \mathrm{HT}$ history means that there were no significant correlation with the increase interdialisis $B B$. ( $p>0.05)$. Correlation interdialisis $B B$ with changing in $B P, R R=2,750 x^{2}=3.84$ and $p=0.050(p=0.050)$ was significantly in positive direction. Conclusion, there was correlation between interdialysis body weight changing with blood pressure elevation. $8 \%$ of those who exposed the rise interdialysis body weight was hypotension.
\end{abstract}

Keywords: BB interdialysis, blood preasure, Haemodialisys.

Info Artikel:

Artikel dikirim pada 11 November 2013

Artikel diterima pada 11 November 2013 


\section{Pendahuluan}

Ginjal berfungsi untuk pengaturan konsentrasi elektrolit dan $\mathrm{pH}$ cairan ekstra seluler (CES) dan mengekresikan sampah nitrogen serta produk sampingan metabolisme lainya dalam bentuk urine. Sel ginjal juga membentuk dan mensekresikan dua hormon, kalsitriol dan eritropoetin 1 .

Prevalensi pasien CKD di Amerika Serikat pada akhir tahun 2002, sekitar 345.000 orang terus meningkat dan insiden gagal ginjal didunia juga mengalami peningkatan terus. Dinegara maju, angka gagal ginjal cukup tinggi. Lebih dari $10 \%$ atau lebih dari 20 juta, berusia 20 tahun atau lebih tua menderitra Cronik Kidney Disease menurut The National Instittute of Diabetes and Digestive and Kidney Disease ${ }^{2}$.

Kejadian morbiditas penyakit ginjal di Indonesia juga mengalami peningkatan. Menurut YAGINA (Yayasan Ginjal Indonesia) dalam Sari, 2009 menjelaskan pada tahun 2007 terdapat 6,7 \% dari penduduk Indonesia sudah mempunyai gangguan fungsi ginjal dengan tingkat sedang sampai berat. Menurut Indonesian Renal Registry (IRR, 2010) di Indonesia pasien gagal ginjal yang melakukan tindakan Hemodialisa mengalami peningkatan dari tahun 2007 jumlah pasien 6862 orang dan tahun 2009 meningkat menjadi 12800 orang. Tahun 2010 meningkat meningkat menjadi 14833 orang yang menjalani pengobatan hemodialisa ${ }^{3}$.

Penelitian ini bertujuan untuk menganalisis perubahan berat badan interdialisis dengan perubahan tekanan darah pasien post hemodialisis di RSUD Saras Husada Purworejo.

\section{Bahan dan Metode}

Penelitian ini dilaksanakan dengan metode survey (observasional) dengan Desain penelitian ini menggunnakan rancangan survei cohort. Dalam penelitian ini pasien dibedakan menjadi dua kelompok yaitu pasien yang kenaikan berat badan interdialisis $>8$ $\%$ (terpapar) dan pasien yang kenaikan berat badannya $<8 \%$ (tidak terpapar), kemudian kedua kelompok tersebut diobservasi tekanan darahnya sebelum dan sesudah dialisis. Penelitian ini dilaksanakan di ruang Hemodialisa RSUD Saras Husada Kabupaten Purworejo Jawa Tengah. Penelitian ini dilaksanakan pada bulan Agustus tahun 2013.

Pengambilan sampel dalam penelitian ini menggunakan teknik Purposive Sampling yakni pengambilan sampel dengan pertimbangan tertentu ${ }^{5}$. Kriteria inklusi adalah kriteria yang perlu dipenuhi oleh setiap anggota populasi yang dapat diambil sebagai sampel, sedangkan kriteria eklusi adalah ciri-ciri anggota populasi yang tidak dapat diambil sebagai sampel ${ }^{4}$. Kriteria inklusi penelitian ini adalah pasien hemodialisa rutin lebih dari tiga bulan, hemodialisa terjadwal frekwensi 2 kali seminggu, durasi HD 4 jam, kesadaran compos mentis, bersedia ikut dalam penelitian, umur 20 tahun sampai 64 tahun. Kriteria eksklusi penelitian ini adalah penderita anemia berat, pasien yang mengkonsumsi obat antihipertensi sebelum hemodialisa, usia lebih dari 65 tahun. Jumlah sampel 20 pasien pada kelompok terpapar dengan kenaikan berat badan intedialisis > 8\% dan 20 pasien pada kelompok yang tidak terpapar dengan kenaikan berat badan interdialisis $<8 \%$.

\section{Hasil dan Pembahasan}

\section{Karakteristik subyek penelitian}

Dari tabel 1.1. Dapat diketahui hasil dari variabel jenis kelamin dengan $p$-value $=0,736$, umur dengan $p$ value $=0,744$, riwayat diabetus melitus (DM) dengan $p$-value $=0,311$ dan riwayat hipertensi dengan $p$-value $=0,185$, artinya dapat disimpulkan tidak mempunyai hubungan yang bermakna secara statistik dengan kenaikan berat badan interdialisis dengan nilai $p$-value lebih dari 0,05.

\section{Analisis Univariat}

a. Kelompok pasien yang terpapar (kenaikan BB interdialisis $\geq 8 \%$ )

Dari hasil analisis didapatkan rata-rata berat badan post HD yang lalu $54,315 \mathrm{~kg}$, Median $51,400 \mathrm{~kg}$, (95\% Cl: 47,118-1,512) dengan standar deviasi 15,3784 $\mathrm{kg}$. Berat terendah $38,5 \mathrm{~kg}$ dan berat tertinggi $114,1 \mathrm{~kg}$. Dari estimasi interval disimpulkan bahwa 95\%diyakini bahwa rata-rata berat badan post hd yang lalu adalah diantara $47,118 \mathrm{~kg}$ sampai $61,512 \mathrm{~kg}$.

Dari hasil analisis didapatkan rata-rata berat badan pre hd $59,935 \mathrm{~kg}$, median $57,600 \mathrm{~kg},(95 \% \mathrm{Cl}$ : $52,280-67,590$ ) dengan standar deviasi $16,3566 \mathrm{~kg}$. Berat terendah $42,6 \mathrm{~kg}$ dan berat tertinggi $124,4 \mathrm{~kg}$. Dari estimasi interval disimpulkan bahwa 95\% diyakini bahwa rata-rata berat badan pre hd adalah diantara $52,280 \mathrm{~kg}$ sampai $67,590 \mathrm{~kg}$.

Dari hasil analisis didapatkan rata-rata berat badan post hd $54,995 \mathrm{~kg}$, median $52,550 \mathrm{~kg}$, $(95 \%$ Cl: 47,508-62,482) dengan standar deviasi 15,9982 $\mathrm{kg}$. Berat terendah $38,4 \mathrm{~kg}$ dan berat tertinggi 118,3 kg. Dari estimasi interval disimpulkan bahwa 95\% diyakini bahwa rata-rata berat badan post hd adalah diantara 47,508 kg sampai $62,482 \mathrm{~kg}$.

Dari hasil analisis didapatkan rata-rata tekanan darah sistole pre HD 164,550 mmHg, median 158,500 mmHg, (95\% Cl: 156,457 - 172,643) dengan standar 
Tabel 1.1 Karakteristik subyek penelitian pasien hemodialisa di RSUD Saras Husada Purworejo tahun 2013

\begin{tabular}{|c|c|c|c|c|c|c|c|}
\hline \multirow[t]{2}{*}{ Varibel } & & \multicolumn{2}{|c|}{$\begin{array}{c}\text { Kelompok tidak terpapar } \\
\text { (kenaikan<8\%) }\end{array}$} & \multicolumn{2}{|c|}{$\begin{array}{l}\text { Kelompok terpapar } \\
\text { (kenaikan } \mathrm{BB} \geq 8 \% \text { ) }\end{array}$} & \multirow[t]{2}{*}{$x^{2}$} & \multirow[t]{2}{*}{ P-value } \\
\hline & & $\mathbf{n}$ & $\%$ & $\mathbf{n}$ & $\%$ & & \\
\hline \multirow[t]{2}{*}{ Jenis kelamin } & Laki-laki & 13 & 32,5 & 14 & 35,0 & \multirow{2}{*}{0,114} & \multirow{2}{*}{0,736} \\
\hline & wanita & 7 & 17,5 & 6 & 15,0 & & \\
\hline \multirow[t]{2}{*}{ Umur } & $\geq 51$ tahun & 13 & 32,5 & 12 & 30,0 & \multirow{2}{*}{0,107} & \multirow{2}{*}{0,744} \\
\hline & $<51$ tahun & 7 & 17,5 & 8 & 20,0 & & \\
\hline \multirow{2}{*}{$\begin{array}{l}\text { Riwayat } \\
\text { penyakitDM }\end{array}$} & $\mathrm{DM}$ & 8 & 20,0 & 5 & 12,5 & \multirow[b]{2}{*}{1,026} & \multirow{2}{*}{0,311} \\
\hline & Tidak DM & 15 & 37,5 & 12 & 30,0 & & \\
\hline \multirow{2}{*}{$\begin{array}{l}\text { Riwayat } \\
\text { penyakit } \\
\text { Hipertensi }\end{array}$} & Hipertensi & 15 & 37,5 & 11 & 27,5 & \multirow[b]{2}{*}{1,758} & \multirow[b]{2}{*}{0,185} \\
\hline & Tidak hipertensi & 5 & 12,5 & 9 & 22,5 & & \\
\hline
\end{tabular}

Sumber: Data Primer

Tabel 2.1. Distribusi frekwensi berat badan dan tekanan darah pasien hemodialisa di RSUD Saras Husada Purworejo Tahun 2013

\begin{tabular}{llllll}
\hline \multicolumn{1}{c}{ Variabel } & \multicolumn{1}{c}{ Mean } & S.D & \multicolumn{1}{c}{ Median } & \multicolumn{1}{c}{ Minimal-Maksimal } & \multicolumn{1}{c}{$\mathbf{9 5 \% \mathbf { C l }}$} \\
\hline BB Post HDYang Lalu & 54,315 & 15,378 & 51,400 & $38,5-114,1$ & $47,118-61,512$ \\
BB Pre HD & 59,935 & 16,356 & 57,600 & $42,6-124,4$ & $52,280-67,590$ \\
BB Post HD & 54,995 & 15,998 & 52,550 & $38,4-118,3$ & $47,508-62,482$ \\
TD Sistole Pre HD & 164,550 & 17,291 & 158,500 & $140,0-197,0$ & $156,457-172,643$ \\
TD Sistole Post HD & 128,700 & 24,127 & 125,000 & $90,0-188,0$ & $177,408-139,992$ \\
TD Diastole Pre HD & 89,900 & 10,833 & 88,500 & $74,0-115,0$ & $84,830-94,970$ \\
TD Diastole Post HD & 74,250 & 9,329 & 73,500 & $57,0-102,0$ & $69,884-78,616$ \\
\hline
\end{tabular}

Sumber: Data Primer

deviasi $17,2915 \mathrm{mmHg}$. TD Sistole terendah 140,0 $\mathrm{mmHg}$ dan TD sistole tertinggi $197,0 \mathrm{mmHg}$. Dari estimasi interval disimpulkan bahwa $95 \%$ diyakini bahwa rata-rata tekanan darah sistole pre hd adalah diantara $156,457 \mathrm{mmHg}$ sampai $172,643 \mathrm{mmHg}$.

Dari hasil analisis didapatkan rata-rata tekanan darah sistole post HD 128,700 $\mathrm{mmHg}$, median 125,000 mmHg, (95\% Cl: 117,408 - 139,992) dengan standar deviasi $24,1271 \mathrm{mmHg}$. TD sistole terendah $90,0 \mathrm{mmHg}$ dan TD sistole tertinggi $188,0 \mathrm{mmHg}$. Dari estimasi interval disimpulkan bahwa 95\% diyakini bahwa rata-rata tekanan darah sistole post hd adalah diantara $117,408 \mathrm{mmHg}$ sampai $139,992 \mathrm{mmHg}$.

Hasil analisis didapatkan rata-rata tekanan darah diastole pre HD $89,900 \mathrm{mmHg}$, median 88,500 mmHg, (95\% Cl: 84,830-94,970) dengan standar deviasi $10,8332 \mathrm{mmHg}$. TD diastole terendah 74,0 $\mathrm{mmHg}$ dan TD diastole tertinggi $115,0 \mathrm{mmHg}$. Dari estimasi interval disimpulkan bahwa 95\% diyakini bahwa rata-rata tekanan darah diastole pre hd adalah diantara $84,830 \mathrm{mmHg}$ sampai $94,970 \mathrm{mmHg}$.

Dari hasil analisis didapatkan rata-rata tekanan darah diastole post HD $74,250 \mathrm{mmHg}$, median 73,500 mmHg, (95\% Cl: 69,884 - 78,616) dengan standar deviasi $9,3295 \mathrm{mmHg}$. TD diastole terendah 57,0 $\mathrm{mmHg}$ dan TD diastole tertinggi $102,0 \mathrm{mmHg}$. Dari estimasi interval disimpulkan bahwa 95\% diyakini bahwa rata-rata tekanan darah sistole post hd adalah diantara $69,884 \mathrm{mmHg}$ sampai $78,616 \mathrm{mmHg}$.

b. Kelompok pasien yang tidak terpapar dengan kenaikan BB interdialisis $<8 \%$

Dari hasil analisis didapatkan rata-rata berat badan post HD yang lalu $54,695 \mathrm{~kg}$, median 54,350 kg, $(95 \%$ Cl: 50,099-59,291) dengan standar deviasi $9,8206 \mathrm{~kg}$. Berat terendah $35,4 \mathrm{~kg}$ dan berat tertinggi $80,5 \mathrm{~kg}$. Dari estimasi interval disimpulkan bahwa 95\% diyakini bahwa rata-rata berat badan post hd yang lalu adalah diantara $50,099 \mathrm{~kg}$ sampai 59,291 $\mathrm{kg}$.

Dari hasil analisis didapatkan rata-rata berat badan pre HD $57,420 \mathrm{~kg}$, median $55,950 \mathrm{~kg},(95 \%$ Cl: 52,815-62,025) dengan standar deviasi 9,8387 $\mathrm{kg}$. Berat terendah $37,5 \mathrm{~kg}$ dan berat tertinggi $84,5 \mathrm{~kg}$. Dari estimasi interval disimpulkan bahwa 95\% diyakini bahwa rata-rata berat badan pre hd adalah diantara $52,815 \mathrm{~kg}$ sampai $62,025 \mathrm{~kg}$.

Dari hasil analisis didapatkan rata-rata berat badan post HD $54,115 \mathrm{~kg}$, median $53,350 \mathrm{~kg}$, $(95 \%$ Cl: 49,512-58,718) dengan standar deviasi 9,8344 $\mathrm{kg}$. Berat terendah $35,2 \mathrm{~kg}$ dan berat tertinggi $80,2 \mathrm{~kg}$. Dari estimasi interval disimpulkan bahwa 95\% diyakini 
Tabel 2.2 Distribusi frekwensi berat badan dan tekanan darah pasien hemodialisa di RSUD Saras Husada Purworejo Tahun 2013

\begin{tabular}{lccccc}
\hline \multicolumn{1}{c}{ Variabel } & Mean & S.D & Median & Minimal-Maksimal & $\mathbf{9 5 \% C l}$ \\
\hline BB Post HD Yang Lalu & 54,695 & 9,820 & 54,350 & $35,4-80,5$ & $50,099-59,291$ \\
BB Pre HD & 57,420 & 9,838 & 55,950 & $37,5-84,5$ & $52,815-62,025$ \\
BB Post HD & 54,115 & 9,834 & 53,350 & $35,2-80,2$ & $49,512-58,718$ \\
TD Sistole Pre HD & 152,10 & 21,581 & 153,000 & $106,0-197,0$ & $141,999-162,201$ \\
TD Sistole Post HD & 134,950 & 21,035 & 140,000 & $93,0-169,0$ & $125,105-144,795$ \\
TD Diastole Pre HD & 88,250 & 13,821 & 91,500 & $58,0-114,0$ & $81,781-94,719$ \\
TD Diastole Post HD & 80,000 & 11,783 & 83,000 & $50,0-98,0$ & $74,485-85,515$ \\
\hline
\end{tabular}

Sumber: Data Primer

Tabel 2.3. Distribusi frekwensi kejadian hipotensi pada pasien hemodialisa di RSUD Saras Husada Purworejo tahun 2013

\begin{tabular}{|c|c|c|c|c|c|c|}
\hline \multirow[t]{2}{*}{ Variabel } & \multicolumn{2}{|c|}{$\begin{array}{c}\text { Kelompok tidak terpapar } \\
\text { (kenaikan<8\%) }\end{array}$} & \multicolumn{2}{|c|}{$\begin{array}{l}\text { Kelompok terpapar } \\
\text { (kenaikan } \mathrm{BB} \geq 8 \% \text { ) }\end{array}$} & \multirow[t]{2}{*}{ Total $\mathbf{n}$} & \multirow[t]{2}{*}{$\%$} \\
\hline & $\mathbf{n}$ & $\%$ & $\mathbf{n}$ & $\%$ & & \\
\hline Hipotensi & 9 & 22,5 & 16 & 40 & 25 & 62,5 \\
\hline Tidak hipotensi & 11 & 27,5 & 4 & 10 & 15 & 37,5 \\
\hline Jumlah & 20 & & 20 & & 40 & 100 \\
\hline
\end{tabular}

Sumber: Data Primer

bahwa rata-rata berat badan post hd adalah diantara $49,512 \mathrm{~kg}$ sampai $58,718 \mathrm{~kg}$.

Dari hasil analisis didapatkan rata-rata tekanan darah sistole pre HD 152,100 mmHg, median 153,000 mmHg, (95\% Cl: 141,999-162,201) dengan standar deviasi $21,5819 \mathrm{mmHg}$. TD sistole terendah 106,0 $\mathrm{mmHg}$ dan TD sistole tertinggi $197,0 \mathrm{mmHg}$. Dari estimasi interval disimpulkan bahwa 95\% diyakini bahwa rata-rata tekanan darah sistole pre hd adalah diantara 141,999 mmHg sampai 162,201 $\mathrm{mmHg}$.

Dari hasil analisis didapatkan rata-rata tekanan darah sistole post HD $134,950 \mathrm{mmHg}$, median $140,000 \mathrm{mmHg},(95 \% \mathrm{Cl}: 125,105-144,795)$ dengan standar deviasi $21,0350 \mathrm{mmHg}$. TD Sistole terendah $93,0 \mathrm{mmHg}$ dan TD sistole tertinggi $169,0 \mathrm{mmHg}$. Dari estimasi interval disimpulkan bahwa 95\% diyakini bahwa rata-rata tekanan darah sistole post hd adalah diantara $125,105 \mathrm{mmHg}$ sampai 144,795 $\mathrm{mmHg}$.

Dari hasil analisis didapatkan rata-rata tekanan darah diastole pre HD 88,250 mmHg, median 91,500 mmHg, (95\% Cl: 81,781-94,719) dengan standar deviasi $13,8217 \mathrm{mmHg}$. TD diastole terendah 58,0 $\mathrm{mmHg}$ dan TD diastole tertinggi $114,0 \mathrm{mmHg}$. Dari estimasi interval disimpulkan bahwa 95\% diyakini bahwa rata-rata tekanan darah hd adalah diastole pre hd antara $81,781 \mathrm{mmHg}$ sampai $94,719 \mathrm{mmHg}$.

Dari hasil analisis didapatkan rata-rata tekanan darah diastole post HD $80,000 \mathrm{mmHg}$, median 83,000 mmHg, $(95 \% \mathrm{Cl}: 74,485-85,515)$ dengan standar deviasi $11,7831 \mathrm{mmHg}$. TD Diastole terendah 50,0 $\mathrm{mmHg}$ dan TD diastole tertinggi $98,0 \mathrm{mmHg}$. Dari estimasi interval disimpulkan bahwa 95\% diyakini bahwa rata-rata tekanan darah sistole post hd adalah diantara $74,485 \mathrm{mmHg}$ sampai $85,515 \mathrm{mmHg}$.

\section{Distribusi frekwensi kejadian hipotensi}

Dari tabel 2.3 dapat diketahui bahwa pasien dengan kenaikan berat badan interdialisis $\geq 8 \%$ sebagian besar pasien mengalami hipotensi yaitu sejumlah 16 pasien atau $40 \%$ dan tidak mengalami hipotensi 4 pasien atau $10 \%$

Dari tabel 2.3 dapat diketahui bahwa pasien dengan kenaikan berat badan interdialisis $<8 \%$ yang mengalami hipotensi yaitu sejumlah 9 pasien atau $22,5 \%$ dan yang tidak mengalami hipotensi 11 pasien atau $27,5 \%$.

Dari keseluruhan jumlah pasien yang diteliti yang mengalami kejadian hipotensi sejumlah 25 pasien atau $62,5 \%$ dan yang tidak hipotensi sejumlah 15 pasien atau $37,5 \%$.

Dari hasil uji Paired T-Test didapatkan $t$ hitung $-12,272$, menunjukan bahwa BB post HD yang lalu lebih rendah dari BB pre $\mathrm{HD}, p$-value $=0,000$ dimana nilai tersebut kurang dari 0,05 maka Ho ditolak artinya ada beda rata-rata antara BB post HD yang lalu dengan BB pre HD dengan selisih (delta $=-4,1725$ ).

Dari hasil uji Paired T-Test didapatkan $t$ hitung 13,934, menunjukan bahwa BB pre HD lebih besar dari BB post $\mathrm{HD}, p$-value $=0,000$ dimana nilai tersebut kurang dari 0,05 maka Ho ditolak artinya ada beda rata-rata antara $\mathrm{BB}$ pre $\mathrm{HD}$ dengan $\mathrm{BB}$ post $\mathrm{HD}$ denganselisih (delta $=4,1225$ ). 
Tabel 2.4. Perbedaan rata- rata berat badan dan tekanan darah pada keseluruhan pasien hemodialisa di RSUD Saras Husada Purworejo tahun 2013.

\begin{tabular}{|c|c|c|c|c|c|}
\hline \multirow{2}{*}{ Variabel } & \multirow{2}{*}{ Mean } & \multirow{2}{*}{ SD } & \multicolumn{3}{|c|}{ Hasil Paired T-test } \\
\hline & & & Delta & $t$ & $p$-value \\
\hline BB post hd yang lalu -BB pre hd & $\begin{array}{l}54,50 \\
58,67\end{array}$ & $\begin{array}{l}12,737 \\
13,383\end{array}$ & $-4,1725$ & $-12,272$ & 0,000 \\
\hline BB pre HD - BB post HD & $\begin{array}{l}58,66 \\
54,55\end{array}$ & $\begin{array}{l}13,383 \\
13,115\end{array}$ & 4,1225 & 13,934 & 0,000 \\
\hline TD Sistole pre HD -TD Sistole post HD & $\begin{array}{l}158,32 \\
131,82\end{array}$ & $\begin{array}{l}20,306 \\
22,565\end{array}$ & 26,500 & 8,415 & 0,000 \\
\hline TD diastole pre HD -TD diastole post HD & $\begin{array}{l}89,08 \\
77,13\end{array}$ & $\begin{array}{l}12,286 \\
10,887\end{array}$ & 11,950 & 6,672 & 0,000 \\
\hline
\end{tabular}

Sumber: Data Primer

Dari hasil uji Paired T-Test didapatkan $p$-value $=0,000$ dimana nilai tersebut kurang dari 0,5 artinya ada beda rata-rata antara TD sistole pre HD dengan TD sistole post HD dengan delta 26,500 dan $t$ hitung 8,415 dapat diartikan bahwa TD sistole pre HD lebih tinggi dibandingkan TD sistole post HD.

Dari hasil uji Paired T-Test didapatkan $p$-value $=0,001$ dimana nilai tersebut kurang dari 0,05 artinya ada beda rata-rata antara TD diastole pre HD dengan TD diastole post HD dengan delta 11,950 dan t hitung 6,672 artinya TD diastole pre HD lebih tinggi dibandingkan TD diastole post HD.

a. Korelasi delta $(\Delta)$ berat badan interdialisis dan delta $(\Delta)$ tekanan darah sistole.

Tabel 4.11. Korelasi BB interdialisis dengan tekanan darah sistole pada pasien hemodialisa di RSUD Saras Husada Purworejo Tahun 2013

\begin{tabular}{lcc}
\hline Variabel & \multicolumn{2}{c}{ Hasil Spearman Rank Test } \\
\cline { 2 - 3 } & $\mathbf{R}$ & $\boldsymbol{p}$ - value \\
\hline Delta $(\Delta)$ (BB interdialisis & 0,478 & 0,002 \\
- delta $(\Delta)$ tekanan darah & & \\
sistole & & \\
\hline
\end{tabular}

Sumber: Data Primer

Dari tabel diatas diketahui nilai $r=0,478$ dan nilai $p$-value $=0,002$ dapat diambil kesimpulan bahwa hubungan berat badan interdialisis dengan tekanan darah sistole menunjukkan hubungan yang sedang, dan berpola positif yang artinya semakin bertambah berat badan maka semakin tinggi terjadi penurunan tekanan darah. Hasil uji statistik didapatkan ada hubungan yang signifikan antara kenaikan berat badan interdialisis dengan tekanan darah sistole dengan $p$-value 0,002 dimana $p<0,005$.

b. Korelasi delta $(\Delta)$ berat badan interdialisis dan delta $(\Delta)$ tekanan darah diastole.

Dari tabel diatas diketahui nilai $r=0,220$ dan nilai $p$-value $=0,172$ dapat diambil kesimpulan
Tabel 4.12. Korelasi BB interdialisis dengan tekanan darah diastole pada pasien hemodialisa di RSUD Saras Husada Purworejo Tahun 2013

\begin{tabular}{lcc}
\hline \multirow{2}{*}{ Variabel } & \multicolumn{2}{c}{ Hasil Spearman Rank Test } \\
\cline { 2 - 3 } & $\boldsymbol{R}$ & $\boldsymbol{p}$ - value \\
\hline Delta $(\Delta)(\mathrm{BB}$ & 0,220 & 0,172 \\
interdialisis - delta $(\Delta)$ & & \\
tekanan darah diastole & & \\
\hline
\end{tabular}

Sumber: Data Primer

bahwa hubungan berat badan interdialisis dengan tekanan darah diastole menunjukkan hubungan yang lemah, dan dari uji statistik didapatkan tidak terdapat hubungan yang signifikan antara berat badan interdialisis dengan tekanan darah diastole $p$-value $=$ 0,172 lebih besar dari 0,005.

c. Hubungan antara perubahan berat badan interdialisis dengan perubahan tekanan darah.

Dari hasil uji statistik hubungan antara berat badan interdialisis dengan kejadian hipotensi pada kelompok pasien dengan kenaikan $\mathrm{BB} \geq 8 \%$ sebanyak 16 pasien $(80 \%)$ dan pada kelompok pasien dengan kenaiakn BB $<8 \%$ sebanyak 9 pasien (45\%). Hasil uji statistik didapatkan $p$-value $=0,050$ yang berarti terdapat hubungan yang signifikan. Dari hasil analisis diperoleh $R R=2,750$ yang artinya pasien dengan kenaikan berat badan interdialisis $\geq 8 \%$ mempunyai resiko 2,75 kali untuk mengalami perubahan tekanan darah kearah hipotensi.

Hasil penelitian yang dilakukan terhadap 20 pasien pada kelompok terpapar dengan kenaikan berat badan interdialisis $\geq 8 \%$ dan 20 pasien tidak terpapar dengan berat badan interdialisis $<8 \%$ terhadap perubahan tekanan darah post hemodialisis.

\section{Karakteristik Pasien}

Hasil penelitian berdasarkan jenis kelamin didapatkan $p$-value 0,736 , umur didapatkan $p$-value 
Tabel 4.13. Hubungan BB interdialisis dengan hipotensi pada pasien hemodialisa di RSUD Saras Husada Purworejo Tahun 2013

\begin{tabular}{|c|c|c|c|c|c|c|c|c|c|}
\hline \multirow{3}{*}{$\begin{array}{l}\text { Kenaikan berat } \\
\text { badan interdialisis }\end{array}$} & \multicolumn{4}{|c|}{ Perubahan tekanan darah } & \multirow{2}{*}{\multicolumn{2}{|c|}{ Total }} & \multirow{3}{*}{ RR } & \multirow{3}{*}{$X^{2}$} & \multirow{3}{*}{ p-value } \\
\hline & \multicolumn{2}{|c|}{ Hipotensi } & \multicolumn{2}{|c|}{ Tidak hipotensi } & & & & & \\
\hline & $\mathbf{n}$ & $\%$ & $\mathbf{n}$ & $\%$ & $\mathbf{n}$ & $\%$ & & & \\
\hline $\mathrm{BB}<8 \%$ & 9 & 45 & 11 & 55 & 20 & 100 & (95\% Cl:1,051- & 3,840 & 0,050 \\
\hline $\mathrm{BB} \geq 8 \%$ & 16 & 80 & 4 & 20 & 20 & 100 & $7,197)$ & & \\
\hline Jumlah & 25 & 62,5 & 15 & 37,5 & 40 & 100 & & & \\
\hline
\end{tabular}

Sumber: Data Primer

0,744 , riwayat penyakit DM didapatkan $p$-value 0,311 dan riwayat penyakit hipertensi didapatkan $p$-value 0,185 . Hasil penelitian ini tidak didapatkan hubungan yang bermakna secara statistik terhadap kenaikan berat badan interdialisis dengan nilai $p$-value lebih dari 0,05.

Dari hasil peneliti ini bahwa faktor jenis kelamin, umur, riwayat penyakit DM dan hipertensi tidak terdapat hubungan yang bermakna secara statistik. Hal ini sesuai dengan penelitian Lolyta (2011) bahwa usia, jenis kelamin, penggunaan obat antihipertensi tidak ada pengaruh yang signifikan terhadap kenaikan berat badan ${ }^{6}$.

Faktor yang berpengaruh terhadap kenaikan berat badan interdialisis antara lain: intake cairan, rasa haus, dukungan sosial dan keluarga, self efficacy, stress.

Intake cairan, prosentase air didalam tubuh manusia $60 \%$, dimana ginjal yang sehat akan berfungsi mengeksesi dan mereabsorbsi air untuk menyeimbangkan osmolaritas ginjal. Pasien gagal ginjal kronik yang menjalani hemodialisa mengalami kerusakan dalam pembentukan urin sehingga menyebabkan kelebihan volume cairan dalam tubuh (Smeltzer \& Bare, 2008).

Self Efficacy yaitu kekuatan yang berasal dari seseorang yang bisa mengeluarkan energi positif melalui kognitif, motivasional, afektif. Self efficacy yang tinggi dibutuhkan untuk memunculkan motivasi dari dalam diri agar dapat mematuhi terapi dan pengendalian cairan dengan baik, sehingga dapat mengatur peningkatan berat badan interdialisis ${ }^{7}$.

Rasa haus, pasien gagal ginjal kronik juga mengalami rasa haus yang berlebihan. Merespon rasa haus normalnya dengan minum, akan tetapi pasien CKD tidak diijinkan untuk berespon dengan cara yang normal terhadap rasa haus yang mereka rasakan. Rasa haus dapat disebabkan oleh masukan sodium, kadar sodium yang tinggi, penurunan potasium, angiotensin II, peningkatan urea plasma, hipovolemia post dialisis dan faktor psikologis ${ }^{7}$.

Dukungan sosial dan keluarga, tindakan hemodialisis dapat menimbulkan stress bagi pasien. Dukungan keluarga dapat meningkatkan kualiatas hidup pasien dan berhubungan dengan kepatuhan pasien untuk menjalani terapi (Soninier,2000).

Stress. Pada pasien Hemodialisis (HD) dapat menyebabkan pasien berhenti memonitoring asupan cairan, bahkan ada juga yang berhenti melakukan terapi HD, kejadian ini dapat berakibat pada perubahan berat badan interdialisis (Potter \& Perry, 2006) ${ }^{3}$.

\section{Distribusi kejadian}

Pada semua kelompok yang terpapar dan tidak terpapar yang menjalani hemodialisis yang mengalami kejadian hipotensi sejumlah 25 pasien atau $62,5 \%$ dan yang tidak hipotensi sejumlah 15 pasien atau $37,5 \%$. Hasil penelitian ini sesuai dengan penelitian Lolyta (2011) kenaikan berat badan interdialisis berpengaruh terhadap tekanan darah $p$-value 0,049 . Hal ini sesuai dengan teori yang dikemukakan Hudak \& Gallo (2010) bahwa kenaikan berat badan interdialisis yang berlebih akan mempengaruhi ultrafiltrasi cairan yang dapat berakibat terjadinya gangguan hemodinamik berupa hipotensi ${ }^{3}$.

Kejadian hipotensi lebih banyak terjadi pada pasien yang terpapar dengan kenaikan BB interdialisis $\geq 8 \%$ dikarenakan berhubungan dengan ultrafiltrasi cairan yang lebih besar dengan kecepatan perpindahan cairan dari insterstitial kedalam intravaskuler. Penurunan volume intravaskuler yang terlalu cepat melebihi pergeseran cairan ekstravaskuler ke intravaskuler akan menyebabkan hipotensi.

3. Korelasi berat badan interdialisis dengan tekanan darah sistol

Pada tabel 4.12 didapatkan nilai r: 0,478 dan nilai $p$-value: 0,002 dapat diambil kesimpulan bahwa hubungan berat badan interdialisis dengan tekanan darah sistole menunjukkan hubungan yang sedang dan berpola positif. Hasil uji statistik didapatkan ada hubungan yang signifikan.

Nugroho (2003) dalam penelitiannya terdapat korelasi antara status volume dengan delta sistolik didapatkan $r=-0,361$ dan $p$-value $=0,036$ terdapat hubungan yang bermakna secara statistik. Kelebihan berat badan interdialisis akan meningkatkan 
resistensi vaskuler dan pompa jantung sehingga akan berpengaruh terhadap peningkatan tekanan darah sistole ${ }^{3}$.

4. Korelasi berat badan interdialisis dengan tekanan darah diastole.

Pada tabel 4.13 didapatkan nilai $r=0,220$ dan $p$-value $=0,172$ dapat diambil kesimpulan menunjukkan hubungan yang lemah dan tidak terdapat hubungan yang signifikan secara statistik. Penelitian ini mendukung penelitian Nugroho (2003) dengan nilai $r=-0,394$ dan $p$ - value $=0,146$, tidak terdapat hubungan yang signifikan antara status volume dan delta tekanan darah diastole.

5. Hubungan antara perubahan berat badan interdialisis dengan perubahan tekanan darah.

Hasil penelitian pada tabel 4.14 didapatkan $X^{2}=3,84$ lebih besar dari $X^{2}$ tabel dan $p$-value $=0,050$ yang berarti terdapat hubungan yang signifikan antara perubahan berat badan interdialisis dengan perubahan tekanan darah. Hasil analisis diperoleh $\mathrm{RR}=2,750$ yang berpola positif yang artinya pasien dengan penambahan kenaikan berat badan interdialisis $\geq 8 \%$ mempunyai resiko 2,75 kali untuk mengalami perubahan tekanan darah kearah hipotensi.

Penelitian ini mendukung pada penelitian Agustriadi (2009) tentang hubungan volume darah relatif terhadap episode hipotensi dengan hasil Beta $=0,46, \mathrm{OR}=1,5$, IK 95\% dan $p$-value $=0,01$

Penambahan berat badan yang signifikan akan berpotensial terjadi hipotensi post dialisis dikarenakan ultrafiltrasi yang tinggi dan cepat. Target dry weight (berat badan kering) terlalu rendah dan fluktuasi kecepatan ultrafiltrasi. Selama ultrafiltrasi , perpindahan cairan dari intravaskuler ke membran dialiser dan dikombinasi penurunan tekanan hidrostastik kapiler memicu perpindahan cairan dari insterstitial kedalam intravaskuler. Penurunan volume intravaskuler yang terlalu cepat melebihi pergeseran cairan ekstravaskuler ke intravaskuler akan menyebabkan hipotensi. Penurunan volume darah akan memicu aktifitas aktivitas saraf parasimpatis mengakibat penurunan curah jantung yang berakibat penurunan tekanan darah. Hipotensi berresiko terjadi penurunan kesadaran, kram otot, pusing, mual, muntah dan rasa tidak nyaman.

\section{Simpulan dan Saran}

\section{Simpulan}

Berdasarkan hasil analisis dan pembahasan, penelitaian ini dapat diambil kesimpulan sebagai berikut :
1. Variabel jenis kelamin, umur, riwayat penyakit DM dan riwayat hipertensi tidak mempunyai hubungan yang bermakna secara statistik dengan kenaikan berat badan interdialisis dengan hasil analisis nilai $p$-value lebih dari 0,05 yaitu jenis kelamin $p$-value $=0,736$, umur dengan $p$ value $=0,744$, riwayat diabetus melitus (DM) dengan $p$-value $=0,311$ dan riwayat hipertensi dengan $p$-value $=0,185$.

2. Terdapat hubungan antara berat badan interdialisis dengan tekanan darah sistole dengan menunjukkan hubungan yang sedang, dan berpola positif yang artinya semakin bertambah berat badan maka semakin tinggi terjadi penurunan tekanan darah dengan hasil analisis diketahui nilai $r=0,478$ dan nilai $p$-value $=0,002$

3. Hubungan berat badan interdialisis dengan tekanan darah diastole menunjukkan hubungan yang lemah dengan hasil analisis nilai $r=0,220$ dan dari uji statistik didapatkan tidak terdapat hubungan yang signifikan antara berat badan interdialisis dengan tekanan darah diastole dengan hasil analisis $p$-value $=0,172$

4. Hubungan peruahan berat badan interdialisis dengan perubahan tekanan darah antara kelompok yang terpapar dan tidak terpapar didapatkan $p$-value $=0,050$, nilai $X^{2}=3,84$ dan nilai $R R=$ 2,750 . Kelompok pasien yang terpapar dengan kenaikan berat badan interdialisis $\geq 8 \%$ beresiko terjadi perubahan tekanan darah ( hipotensi ) post hemodialisa 2,75 kali dibandingkan kelompok tidak terpapar dengan kenaikan berat badan interdialisis $<8 \%$.

\section{Saran}

1. Bagi RSUD Saras Husada Purworejo Khususnya unit hemodialisa untuk membuat standar asuhan keperawatan dalam membatasi kenaikan berat badan interdialisis pasien hemodialisa kurang dari $8 \%$. Perawat hemodialisa dapat memberikan edukasi pada pasien dan keluarga tentang resiko penambahan berat badan interdialisis lebih dari $8 \%$.

2. Bagi pasien hemodialisa dan masyarakat umum Hendaknya pasien dan keluarga pasien hemodialisa dapat mengatur kenaikan kenaikan berat badan interdialisis kurang dari $8 \%$.

3. Bagi peneliti lain

Bagi Peneliti selanjutnya hendaknya melakukanpenelitian lebih lanjut dengan variabel berbeda antara lain faktor volume cairan, kadar hematokrit dan albumin, profil ultrafiltrasi dan lainlain yang dapat mempengaruhi kualiatas hidup pasien CKD. 


\section{Daftar Pustaka}

1. Hudak, Carolyn M., Barbara M.Gallo. Keperawatan Kritis: Pendekatan Holistik. Ed 6. Volume 2. AlihBahasa: Monica Ester, Made Kariasa,Made Sumarwati. Efi Afifah; Editoredisi bahasa Indonesia: YasminAsih, EGC: Jakarta 2010

2. NIDKK (The National Instittute of Diabetesand Digestive and Kidney Disease); diunduh dari http://www.nidkk.nih.gov. Tanggal 19 Mei2013 jam 22.35 wib; 2010

3. Indonesian Renal Registry,. 3 Report Of Indonesian Renal Registry. Pernefri:Jakarta; 2010

4. Notoatmodjo, Soekidjo, Metodologi Penelitian Kesehatan. Rineka Cipta: Jakarta; 2010

5. Machfoedz, Ircham, Metodologi Penelitian Kuantitatif \& Kualitatif (Bidang Kesehatan,
Keperawatan, Kebidanan, Kedokteran). Fitramaya: Yogyakarta; 2010

6. Lolyta, Rika, Ismonah, Achmad Solehan. Analisis Faktoryang Mempengaruhi Tekanan Darah Hemodialisis padaPasien Gagal Ginjal Kronik (Studi Kasus di RS TelogorejoSemarang ). Jurnal IImu Keperawatan dan Kebidanan. Diunduh dari http://ejournal.stikestelogorejo.ac.id/index.php/ ilmukeperawatan/article tanggal 25-06-2013 jam 00.45wib; 2011

7. Istanti, Y. P. Faktor-Faktor yangberkontribusi terhadap interdialytic weight gain (IDWG) pada pasien chronic kidney disease (CKD) di Unit Hemodialisis RS PKU Muhammadiyah Yogyakarta. Jurnal Universitas Indonesia, http:// www.digilib.ui.ac.id/file?file=pdf/abstrak-125543. pdf. diunduh tanggal 25 Agustus 2013 jam 13.15 wib; 2009. 